\title{
Understanding the Variability of $Z-R$ Relationships Caused by Natural Variations in Raindrop Size Distributions (DSD): Implication of Drop Size and Number
}

\author{
Abé D. Ochou ${ }^{{ }^{*}}$, Eric-Pascal Zahiri ${ }^{1}$, Bakary Bamba ${ }^{1}$, Manlandon Koffi $^{2}$ \\ ${ }^{1}$ Laboratoire de Physique de l'Atmosphère et Mécanique des fluides (LAPA-MF), Université de Cocody-Abidjan, \\ Abidjan, Côte d'Ivoire \\ ${ }^{2}$ Institut National Polytechnique Houphouët-Boigny, Yamoussoukro, Côte d'Ivoire \\ E-mail:ochoud@yahoo.com \\ Received May 9, 2011; revised June 13, 2011; accepted July 13, 2011
}

\begin{abstract}
In the issue of rainfall estimation by radar through the necessary relationship between radar reflectivity $Z$ and rain rate $R(Z-R)$, the main limitation is attributed to the variability of this relationship. Indeed, several previous studies have shown the great variability of this relationship in space and time, from a rainfall event to another and even within a single rainfall event. Recent studies have shown that the variability of raindrop size distributions and thereby $Z-R$ relationships is therefore, more the result of complex dynamic, thermodynamic and microphysical processes within rainfall systems than a convective/stratiform classification of the ground rainfall signature. The raindrop number and size at ground being the resultant of various processes mentioned above, a suitable approach would be to analyze their variability in relation to that of $Z-R$ relationship.In this study, we investigated the total raindrop concentration number $N_{T}$ and the median volume diameter $D_{0}$ used in numerous studies, and have shown that the combination of these two 'observed' parameters appears to be an interesting approach to better understand the variability of the $Z-R$ relationships in the rainfall events, without assuming a certain analytical raindrop size distribution model (exponential, gamma, or log-normal). The present study is based on the analysis of disdrometer data collected at different seasons and places in Africa, and aims to show the degree of the raindrop size and number implication in regard to the $Z-R$ relationships variability.
\end{abstract}

Keywords: Raindrop Size Distribution, Radar Reflectivity Factor, Rain Rate, Median Volume Diameter, Total Number of Drops Per Unit Volume, Z-R Relationship, Convective Rain, Stratiform Rain, Squall Lines, Thunderstorm

\section{Introduction}

In the study of rainfall, one parameter of interest to estimate with regard to rain drop size distributions (DSD) is the rain rate $R$. It can be measured from the ground using rain gauges and weather radar.The nature of space-time radar measurements represented by the reflectivity factor $Z$ has generated so much interest that many studies have focused on finding connections to bring it in intensity [1-12]. Thus, numerous studies based on the measurement of DSD in precipitation around the world continue to show that empirical expression of the form $Z=A R^{b}$ is a suitable relation to describe the relationship between these two parameters. The fundamen- tal reason for the existence of such power law relationships is the fact that $Z$ and $R$ are related to each other via the raindrop size distribution. However, investigations on the establishment of these relations have shown and continue to show a great variability from a rainfall event to another, within a given rainfall event and from a type of precipitation to another [7-10,13]. For the case of Africa, the variability of $Z-R$ relationships is widely documented by works of Sauvageot and Lacaux [4], Nzeukou et al. [11], Moumouni et al. [12], Russell et al. [14]. Thus, since $Z-R$ relations proliferate in literature, it is difficult to know if an instantaneous rain rate calculated with a fixed $Z-R$ relation is necessarily correct, even if rainfall accumulations should be reasonable 
when an appropriate climatological $Z-R$ relation is used. The rain rate $R$ and the reflectivity factor $Z$ being related theoretically to the statistical moments of DSD, the multiplicity of their relationship would be primarily the result of the spatial and temporal variability of the DSD [15]. Steiner et al. [16] also argued that the relationship between $Z$ and the rain rate $R$ is very dependent on the characteristics of drop size distributions and their evolution with rain rate. In other words, natural variations of DSD characteristics between type of rain and from storm to storm induce a variability in the $Z-R$ relations which affect the quantitative estimation of rain rate from radar reflectivity.

To improve the accuracy of rainfall estimation by radar, numerous studies have given special attention to the determination of $Z-R$ relationships valid for different climatic zones and particularly for different types of precipitation since many authors have strongly suggested the coexistence of distinctly different convective and stratiform DSDs within tropical systems [5]. In special case of tropical Africa the convective and stratiform modes of rainfall are especially important because precipitating clouds often organize into mesoscale convective systems containing the two distinctive environments. Joss and Waldvogel [2] showed that application of $Z-R$ relationships for each type of precipitation (convective or stratiform) would significantly increase the quality of radar measurements of rainfall at daily time step. In that scope, the precipitating systems are, on the basis of rainfall patterns or defined criteria, generally classified by type of precipitation with convective and stratiform parts and sometimes a transition zone [5,17-21] between both when considering rainfall events such as squall lines.

Nevertheless, various investigations have revealed a variety of situations: Yuter and Houze [17] attribute to convective rains a multiplicative factor $A$ higher than in stratiform rain while Tokay and Short [5], Atlas et al. [19], Narayana et al. [22], Maki et al. [7] show that the factor $A$ of the stratiform part is about twice higher than the convective part, the exponent $b$ varying a bit in both cases. Such disparities, suspected to be a cause of underestimation or overestimation of rainfall from measured radar reflectivity, implicitly highlight three important issues:

- the fact that multiple rain rates can be associated with the same reflectivity because of variations in the drop size distribution;

- the problem of characterizing the nature of rainfall and the reliability of partitioning algorithms in stratiform/convective only according to the ground signature of rainy events or following drop size distribution characteristics such as median volume di- ameter [17];

- the difficulty of linking a $Z-R$ relationship to a prevailing physical or microphysical process which leads to the formation or affects the DSD due to the variety of processes in each type of rain.

The latter issue was addressed recently by Lee and Zawadzki [10] through an analysis of the DSD variability at different scales (climatologic, daily, within one day, between physical processes and within a physical process) and its implication on the $Z-R$ relationship. Their work showed that the DSD variability and therefore that of $Z-R$ relationship is more the result of complex dynamic, thermodynamic and microphysical processes within rainfall systems than a convective/stratiform classification of the ground rainfall signature. Similar work has been conducted by Rosenfeld and Ulbrich [23] throughout a notable comprehensive review which ultimate goal was to define the dominant properties of the drop size distribution, their microphysical origin, and their association with the physical characteristics of the storm responsible for their generation. They explored the question of the connections between raindrop size distribu -tions and $Z-R$ relationships from the combined approach of rain-forming physical processes (such as coalescence, breakup, evaporation, size sorting by drafts, ...) that shape the DSD, and a formulation of the DSD into the simplest free parameters of the rain intensity $R$, rain water content $W$ and median volume diameter $D_{0}$. Thereby, they suggested that their results may be used to illustrate the effects on the coefficient $A$ and exponent $b$ of each of the various physical processes. Lee and Zawadzki [10] as well as Rosenfeld and Ulbrich [23] came to the conclusion that the classification or identification of various physical processes within precipitating systems is essential to reduce the rainfall estimation errors through the $Z-R$ relationship.

In the present work, we do not discuss the physical and microphysical processes underlying the variability of $Z-R$ relationship, which would require a description of the vertical structure of precipitating systems from volumetric radar measurements, for example. However, as the raindrop number and size at ground are the result of different processes mentioned above, a suitable approach would be to analyze their variability in relation to that of $Z-R$ relationships at the rainfall event scales. Such a study is interesting as some authors [10,24,25] reported that the DSD variability explains $30 \%$ to $50 \%$ of errors in the rain rate $R$ estimation using the single traditional $Z-R$ method. Because of this DSD variability, the precipitations from different types of cloud may have similar intensities even though the associated couples "diameter-number of raindrops" behave differently. Thus, it appeared essential to study simultaneously the behavior 
Table 1. Data base description. $S L$ (Squall Lines), $A L L$ (whole rainy events).

\begin{tabular}{|c|c|c|c|c|c|c|}
\hline \multirow{2}{*}{ Location } & \multirow{2}{*}{ Coordinates (Altitude) } & \multirow{2}{*}{ Observing Period } & \multicolumn{4}{|c|}{ Events number/1 min. Spectra number } \\
\hline & & & $S L$ & Thunderstorm & Stratiform & $A L L$ \\
\hline \multirow{4}{*}{$\begin{array}{c}\text { Abidjan (Côte } \\
\text { d'Ivoire) }\end{array}$} & \multirow{4}{*}{$\begin{array}{c}5^{\circ} 25 \mathrm{~N}-4^{\circ} \mathrm{W} \\
(40 \mathrm{~m})\end{array}$} & 1986 (Jun., Sept. - Dec.) & $05 / 681$ & $15 / 1098$ & $02 / 179$ & $22 / 1958$ \\
\hline & & 1987 (Feb. - Dec.) & $20 / 2633$ & $82 / 5198$ & $17 / 2006$ & $119 / 9837$ \\
\hline & & 1988 (Feb. - Jun.) & $10 / 2000$ & $26 / 1748$ & $05 / 548$ & $41 / 4296$ \\
\hline & & 1986-1987-1988 & $35 / 5314$ & $123 / 8044$ & $24 / 2733$ & $182 / 16091$ \\
\hline \multirow{3}{*}{ Boyele (Congo) } & \multirow{3}{*}{$\begin{array}{c}2^{\circ} 50 \mathrm{~N}-18^{\circ} 04 \mathrm{E} \\
(330 \mathrm{~m})\end{array}$} & 1988 (May - Jul., Sept. - Dec.) & $25 / 5525$ & $25 / 1434$ & $11 / 1717$ & $61 / 8676$ \\
\hline & & 1989 (Mar. - Jun.) & $10 / 2243$ & $19 / 2530$ & $6 / 644$ & $35 / 5417$ \\
\hline & & 1988-1989 & $35 / 7768$ & $44 / 3964$ & $17 / 2361$ & $96 / 14093$ \\
\hline \multirow{3}{*}{ Niamey (Niger) } & \multirow{3}{*}{$\begin{array}{c}13^{\circ} 30 \mathrm{~N}-2^{\circ} 10 \mathrm{E} \\
(220 \mathrm{~m})\end{array}$} & 1989 (Jul. to Sept.) & $09 / 1379$ & $13 / 1328$ & $01 / 55$ & $23 / 2762$ \\
\hline & & 1991 (Aug.) & $03 / 357$ & $02 / 94$ & $02 / 146$ & $07 / 597$ \\
\hline & & $1989-1991$ & $12 / 1736$ & $15 / 1422$ & $03 / 201$ & 30/3359 \\
\hline \multirow{5}{*}{ Dakar (Senegal) } & \multirow{5}{*}{$\begin{array}{c}14^{\circ} 34 \mathrm{~N}-17^{\circ} 29 \mathrm{~W} \\
(30 \mathrm{~m})\end{array}$} & 1997 (Jul. to Oct.) & $04 / 699$ & $12 / 1795$ & $03 / 466$ & $19 / 2960$ \\
\hline & & 1998 (Jul. to Sept.) & $11 / 2581$ & $16 / 1921$ & $02 / 136$ & $29 / 4638$ \\
\hline & & 1999 (Jul. to Sept.) & $08 / 1839$ & $13 / 1972$ & $03 / 591$ & $24 / 4402$ \\
\hline & & 2000 (Jul. to Oct.) & $14 / 2247$ & $11 / 1470$ & $07 / 1152$ & $32 / 4869$ \\
\hline & & $1997-2000$ & $37 / 7366$ & $52 / 7158$ & $15 / 2345$ & $104 / 16869$ \\
\hline
\end{tabular}

of these two parameters that characterize the DSD to better quantify their influence on the $Z-R$ relationship which variability within precipitations still raises many questions. With this in mind, Atlas et al. [19] studied the $Z-R$ relationships variations within rainfall events taking into account the variability of the median volume diameter $D_{0}$ and that of the intercept parameter $N_{0}$ of an exponential or gamma theoretical function.

Without assuming a certain drop size distribution model, we propose in this study, to use two observed parameters namely the total raindrop number per unit volume (or total number concentration) $N_{T}$ and the median volume diameter $D_{0}$ to show that the $Z-R$ relationship variability in samples taken throughout rainy event scale and at different climatic sites, depends only on the combined effect of the raindrop size and number, an effect taken into account by the ratio of these two DSD integrated variables. Thus, this work ultimately aims to provide insight to the fundamental causes of the systematic differences in $Z-R$ relations. To reach such a conclusion, we analyze all the particle size spectra collected by the Joss and Waldvogel disdrometer type at four observation sites in Tropical Africa, each representing a different type of climate.

Section 2 gives a brief description of the database used here and deals with the convective-stratiform discrimination method of the drop size spectra. A classification of different rain events is also done according to the fact that they are stormy, stratiform or squall line event. Section 3 is devoted to the analysis of $Z-R$ variability relative to that of the DSD at rainfall event scale. Section 4 discusses the contribution of the raindrops size and number observed minute by minute, in the variability of $Z-R$ and emphasizes the simultaneous consideration of these two parameters to explain this variation regardless of analytical forms (exponential, gamma or lognormal). Section 5 schematizes various situations that justify and allow understanding the great disparity of $Z-R$ relationships in precipitation. A conclusion which brings together the main results is given in Section 6.

\section{Data Base and Types of Analyzed Events}

\subsection{Observation Sites and Data}

The dataset used in this study was gathered with a Joss and Waldvogel [26] RD-69 disdrometer type in four African sites located in different climatic zones (Figure 1) at different periods listed in Table 1. This table presents the essential features of the database including 50412 one-minute spectra observation of rain covering 25 classes of raindrops diameter ranging from $0.3 \mathrm{~mm}$ to 5.2 $\mathrm{mm}$ at regular intervals of width $0.2 \mathrm{~mm}$. To infer the drop density from disdrometer measurements at ground, we use the fall velocity formulae of Atlas et al. [27] $V(D)=9.65-10.3 \exp (-0.6 D)$, where $D$ and $V(D)$ are expressed in $\mathrm{mm}$ and $\mathrm{m} \cdot \mathrm{s}^{-1}$. The measures cover different climatic zones (Coastal Equatorial for Abidjan, continental humid Equatorial in Boyele, continental Sahelian zone in Niamey and Dakar located in a coastal Sahelian zone) in Africa and therefore different types of precipitating systems. Such a database, although not carried out simultaneously at different sites, is the guarantee of a good climatologically statistics study of the physical characteristics of precipitation at both seasonal and rainfall event scales. The present study relies on this latter scale ranging from minutes to hours. To this end, the database consists of 412 major rain events (Table 1) de- 


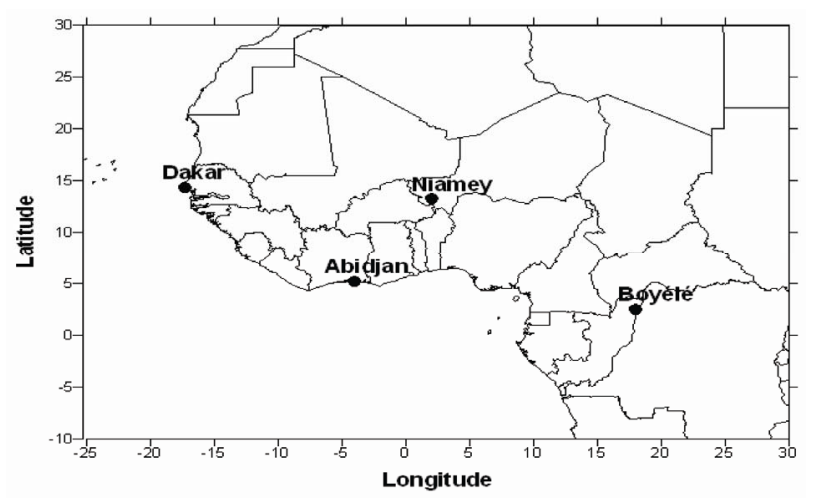

Figure 1. Geographical location of the rainfall measurement data sites by the aid of disdrometer.

rived from the split of one-minute continuous data and analyzed in this paper.

\subsection{Precipitating Systems and Categorizing Precipitation Types for DSD Data}

In the study of precipitations, notably warm or liquid rain, precipitation types are associated with clouds types in a given climate zone. Since the nature of the precipitation reflects the nature of the microphysical processes of hydrometeor formation, growth, and transformation, it is especially important to distinguish different modes of rainfall occurring in Africa tropical regions. Thus, we can analyze the similarities and differences between raindrop size distributions in various precipitation regimes and their impact on $Z-R$ relationships. At surface, considering single punctual measurements, as in case of this study, the value of the rain rate $R$ and its temporal variability can be the simplest way to identify the type of precipitation but did not provide information on microstructure of rain. Figure 2 shows the temporal evolution of rainfall rate and DSD related to different types of precipitation. There are convective rainfall associated with squall lines and isolated thunderstorms and rain associated with the non convective or stratiform clouds. Widespread stratiform rains, usually from stratus clouds, are characterized by low and moderate intensities less than or equal to $10 \mathrm{~mm} \cdot \mathrm{h}^{-1}$, variable or stable over time and can last several hours. They are usually observed in monsoon periods or short dry season in tropical areas. Figure 2(b) shows an example of these rains in Abidjan. Rain from thunderstorm, are yielded by localized and isolated precipitating convective clouds characterized by one cell (Figure 2(c)) or more convective cells called clusters (Figure 2(d)). The former (called unicellular convective system) are relatively limited in time (about 20 minutes to an hour) when the latter, multi-cellular may last several hours. These rainy convective systems are characterized by high intensities which can reach more than $100 \mathrm{~mm} \cdot \mathrm{h}^{-1}$ in the active phase of storm cells. Figure 2(c) and Figure 2(d) show two typical cases of stormy rainfall in Abidjan. Finally, squall lines consist of precipitation generated by convective clouds multi-cellular cumulonimbus, well organized. Their time signature at surface is characterized by two distinctive regions: a leading part called convective of relatively short duration (20 - 30 minutes) and characterized by high rain rates (up to 100 to $150 \mathrm{~mm} \cdot \mathrm{h}^{-1}$ ) and another part called stratiform rain region which can last 1 to 6 hours with little varying, moderate and low (below $10 \mathrm{~mm} \cdot \mathrm{h}^{-1}$ ) intensities. Figure 2(a) shows a typical example of squall lines observed in Abidjan with both convective (referred by letter C) and stratiform region (referred by letter S).

Because characteristics of these regions of squall lines are different, it is also important to categorize the DSD data according to whether the spectra were obtained in region of convective or stratiform precipitation. According to the standard convective-stratiform definition, precipitation type can be identified in the presence of simultaneous observations of vertical air velocities and the terminal fall speed of hydrometeors $[18,28]$ or based upon reflectivity structure $[17,29]$. None of these two methods of distinguishing convective from stratiform rain is applicable in our study because neither radar data nor draft magnitudes have been simultaneously collected during measurements periods of raindrop size distribution used here. Since these observations are rare, Tokay and Short [5] and Tokay et al. [18] determined the separation between convective and stratiform precipitation on the basis of a jump in the intercept parameter $\left(N_{0}\right)$ of the gamma-fitted DSD, following the physical arguments of Waldvogel [30]. Nevertheless, as we do not consider specific theoretical DSD model in this study, precipitation was classified as convective or stratiform basing on hyetograph (time evolution of rain rate for a given rainy event) according to the method proposed by Testud et al. [6] and successfully applied by Moumouni et al. [12] and Gosset et al. [31] on recent African rainfall observed in northern Benin during the intensive campaign of the international African Monsoon Multidisciplinary Analysis (AMMA).

This approach is based on the fact that stratiform precipitations are low in intensity and have a large horizontal extension. Thus, for a sequence of values $\left\{R_{i}\right\}$ intensities of rainfall from the hyetograph of a squall line, a spectrum $k$ is classified as stratiform only if its intensity $R_{k}$ and those of its 20 closest neighbors spectra $\left(R_{10-k}\right.$ to $R_{10+k}$ ) are all smaller than the threshold value of 10 $\mathrm{mm} \cdot \mathrm{h}^{-1}$. Otherwise, this spectrum is classified convective. In this latter case, the 20 adjacent spectra are also considered as convective. In this way, such a criterion allows 

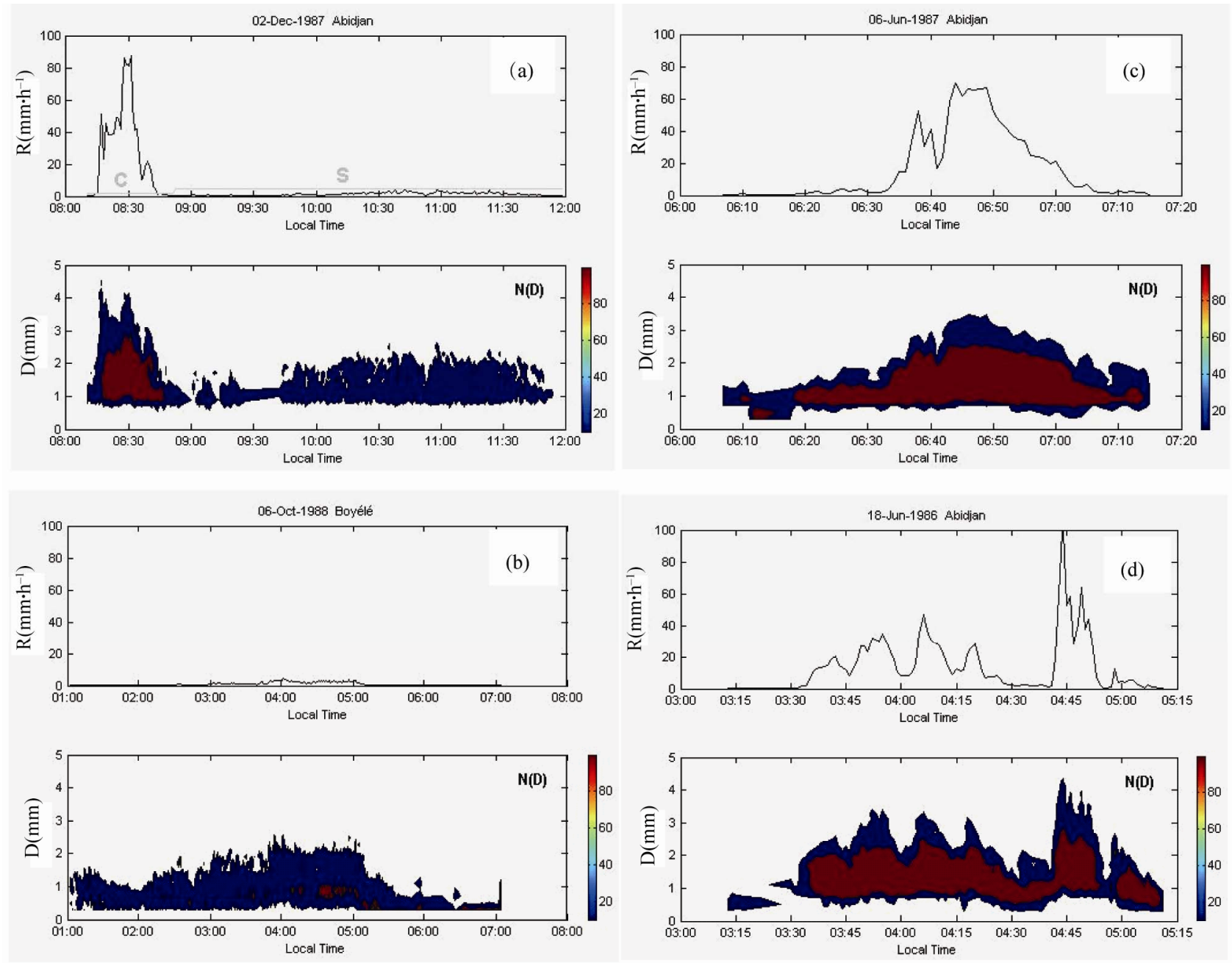

Figure 2. Temporal evolution of rainfall rate and raindrop distributions for various types of rainfall systems studied in this work: (a) squall line, (b) stratiform rainfall event (c) and (d) Tunderstorms rain events.

to classify as convective, spectra with intensity less than $10 \mathrm{~mm} \cdot \mathrm{h}^{-1}$ which is found by several authors as having a stratiform character. Thus, with this method even low rain rates can be classified as convective if they are in a region of the storm with rainfall gradients [31]. Figure 2(a) (the top panel) illustrates this classification on the 02 December 1987 squall lines observed in Abidjan (Côte d'Ivoire) which is characterized by convective (C) and stratiform $(\mathrm{S})$ rains.

\section{Variability of $Z-R$ relationships in connec- tion with that of DSD at the rainfall event scale}

In the scope of this work, we discussed the fact that previous studies have shown the great variability of $Z-R$ relations from system to system, between rain types and even within a same convective system. Investigations done on this relationship in different types of precipita- tion have resulted in two opposite 'schools' particularly with respect to the multiplicative factor (prefactor) $A$ of this relationship. One of these 'schools' [17] suggests that this prefactor is higher in the convective part than in the stratiform part, while the other [5,7,19,22] shows the opposite. In this work in general and the present section, we propose to show the existence of these two contrasting situations in observed precipitations, and investigate the reasons that favor one or the other situation. To this end, we first only use the rainfall events in the form of squall lines. Then, this approach is also applied to other types of rain (thunderstorms rain and stratiform rain) to illustrate the variability from system to system for a same type of rain considered. Figure 3 exhibits all these variability cases of $Z-R$ relations.

The analysis of Figure 3 shows that the coefficient $A$ and the exponent $b$ of the $Z-R$ relationships vary significantly both within the same precipitation type and from system to system but the variations are least accurate for 

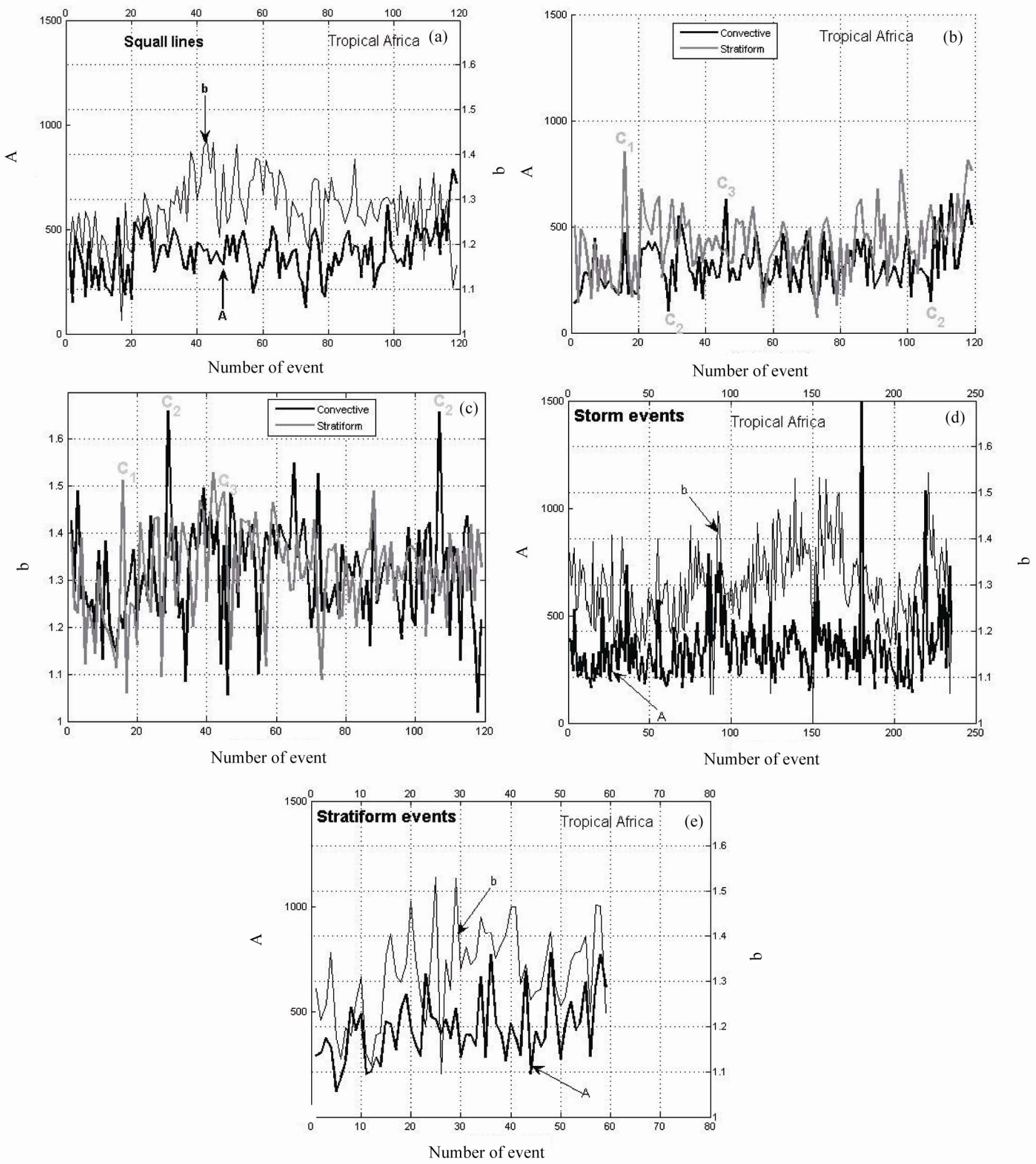

Figure 3. Variability of the coefficients $A$ and $b$ of the $Z-R$ relationship from a rainfall event to another: (a) case of squall lines, (b) and (c) convective and stratiform parts of squall lines, (d) stormy rain, (e) stratiform rain. $C_{1}, C_{2}, C_{3}$ indicate $s p e-$ cific cases of convective-stratiform comparison of $A$ and $b$ values.

exponent $\mathrm{b}$. Although there is an appreciable variability in the coefficients of these $Z-R$ relationships associated with differences in rainfall type and within a same rainfall type, there seems to be in a well-defined envelope comprising most relationships reported in literature and quoted by work from Uijlenhoet [32]. Table 2 which presents statistics of the coefficient and exponent of the relation $Z-R$, illustrates these fluctuations. Whatever rain 
Table 2. Statistics of coefficient and exponent of the relation between $Z$ and $R$. Mean, Standard deviation, minimum, and maximum values for various type of rainfall.

\begin{tabular}{cccccc}
\hline Rain types & Z-R Coef. & Mean & Std dev & Min & Max \\
\hline \multirow{2}{*}{ Squall lines $(S L)$} & $A$ & 384 & 116 & 127 & 788 \\
& $b$ & 1.28 & 0.07 & 1.03 & 1.43 \\
Convective (SL) & $A$ & 319 & 117 & 104 & 654 \\
& $b$ & 1.31 & 0.11 & 1.02 & 1.66 \\
Stratiform (SL) & $A$ & 420 & 150 & 72 & 852 \\
& $b$ & 1.31 & 0.10 & 1.06 & 1.53 \\
Thunderstorms & $A$ & 344 & 165 & 141 & 1924 \\
& $b$ & 1.30 & 0.09 & 1.0 & 1.54 \\
Stratiform events & $A$ & 417 & 153 & 118 & 777 \\
& $b$ & 1.32 & 0.10 & 1.09 & 1.53 \\
All events & $A$ & 366 & 153 & 118 & 1924 \\
& $b$ & 1.30 & 0.09 & 1.0 & 1.54 \\
\hline
\end{tabular}

type, the coefficient $A$ of the $Z-R$ relationship shows a great standard deviation corresponding to a variation greater than $30 \%$ to the mean value of the related sample. Specifically, Convective rainfall from squall lines is characterized by prefactor $A$ varying from 104 to 654 , with a mean value of 314 and a standard deviation of 117 . This standard deviation corresponds to a variation of $37 \%$ to the mean value. All the $A$ values for stratiform sample derived from squall lines are within the range 72 $<A<852$ corresponding to a similar variation (36\%) to the related mean value as in the convective case in spite of a distinctive mean value (420). An exceptional very large $A$ coefficient $(A=1924)$ is noted in thunderstorm rainfall sample. Such values of the prefactor $A$ (2754 and 1471) has been also reported by Ulbrich and Atlas [33] analyzing DSD data from two major convective cells of a continental storm observed at Arecibo, Puerto Rico (see their Table 1). They probably refer to extreme rainfall events.

In contrast to the coefficient $A$ of the $Z-R$ relationship, the exponent $b$ presents a relatively small variation (Table 2), with mean value of 1.3 whatever rainfall type. The standard deviation values of different rainfall types account for variations under $9 \%$ to their respective mean value.

Moreover, on the one hand, the results, especially in the events described as squall lines, exhibit several situations illustrated by $\mathrm{C}_{1}, \mathrm{C}_{2}$ and $\mathrm{C}_{3}$ in Figures 3(b) and (c):

$$
\begin{array}{ll}
A_{c}<A_{S} \text { and } b_{c}<b_{s} & \left(\text { case } \mathrm{C}_{1}\right. \text { in Figures 3(b) and (c)) } \\
A_{c}<A_{S} \text { and } b_{c}>b_{s} & \left(\text { case } \mathrm{C}_{2}\right. \text { in Figures 3(b) and (c)) } \\
A_{c}>A_{S} \text { and } b_{c}<b_{s} & \left(\text { case } \mathrm{C}_{3}\right. \text { in Figures 3(b) and (c)). }
\end{array}
$$

The coefficients $A_{c}$ and $b_{c}$ are the values of factors $A$ and $b$ of the $Z-R$ relationship in the convective region whereas $A_{s}$ and $b_{s}$ are those for the stratiform part of the squall lines. On the other hand, rainy events characterized by rain called stratiform (widespread and low rain- fall) where the intensities hardly reach $10 \mathrm{~mm} \cdot \mathrm{h}^{-1}$, and localized stormy rain have also different $Z-R$ relations from system to system considering each category of rain.

These examples confirm the great variability of $Z-R$ relations in precipitation and allow to accept the results of Yuter and Houze [17] who obtained $A_{c}>A_{s}$ and those of Tokay and Short [5] who found on the contrary that $A_{c}$ $<A_{s}$. Their respective results can be justified by the fact that they likely used squall lines related with different intrinsic characteristics (raindrops number and size). Indeed, Tokay and Short [5] observed two distinct groups of DSD for the same rain rate $\left(R=6 \mathrm{~mm} \cdot \mathrm{h}^{-1}\right)$, including one being dominated by small drops and the other by large drops, and both derived from convective and stratiform parts respectively of a squall lines. Yuter and Houze [17], unlike Tokay and Short [5], found that stratiform precipitation contains a broad range of drop spectra especially both large and narrow DSDs exist within the same stratiform region of squall lines data. From this, we can recognize, as argued Chandrasekar et al. [34], the connection between DSD variability and the values of $A$ and $b$. However, the crucial issue to be concerned in should be find an interpretation of the coefficients of resulting power law $Z-R$ relationships in terms of the parameters of the raindrop size distribution. In other words, understand how the coefficients of such relationships are related to the parameters of the raindrop size distribution may help to explain their variability. Previous works by Heinrich et al. [35], Rosenfeld and Ulbrich [23], and Lee and Zawadzki [10], as mentioned in introduction, have revealed the connection of dominant physical processes with $Z-R$ relationship. However, the modifications of the DSD by these physical processes generally lie in changes in drop size and number. For instance, Heinrich et al. [35] have shown clear evidence of a relationship between riming process, drops concentration (represented by $N_{0}$ parameter of a gamma function) and the median volume diameter, $D_{0}$. They showed that both $N_{0}$ and $D_{0}$ exhibit dramatic changes as riming increased, at time without changes in rain rate. Rosenfeld and Ulbrich [23] have shown the essential features of DSD (in terms of drop size and number) resulting from coalescence, break-up, accretion, size sorting by drafts, wind shear, and evaporation. From this, obviously tackling such connection between DSD variations and the values of $A$ and $b$ implies simultaneous analysis of both drops size and number.

The next section of this paper is devoted to the outline of the approach to take into account the combined effect of the DSD characteristics (drop size and number) and understand its implication in the variability of $Z-R$ relationships. 

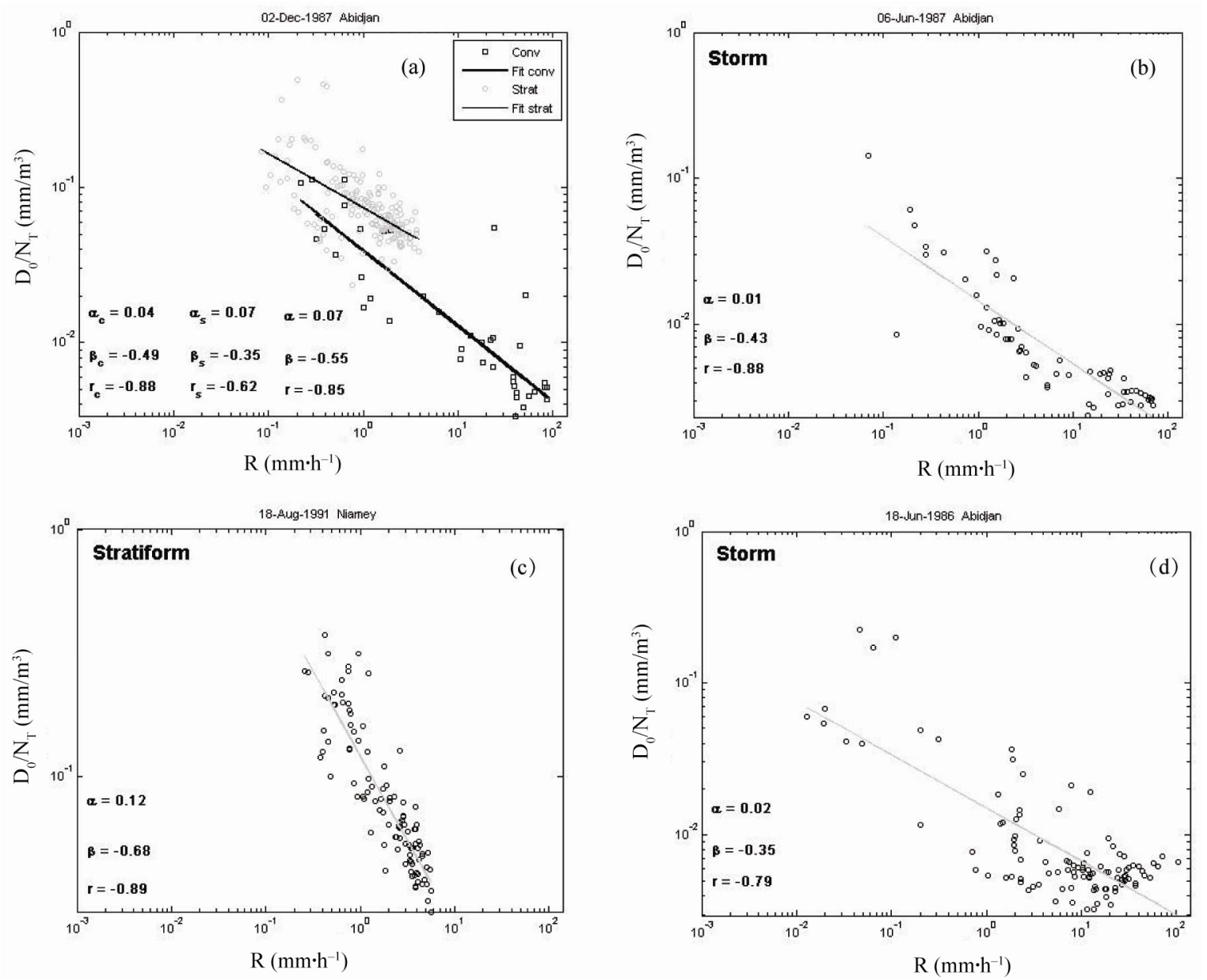

Figure 4. Scatter plots $\left(D_{0} / N_{T}, R\right)$ and fitted curves on different samples: (a) case of a squall line divided into convective-stratiform, (b) case of a widespread stratiform rain, (c) case of a single cell storm, (d) case of a multi-cellular storm.

\section{Implication of the Drops Size and Number in the Variability of $Z-R$ Relations}

\subsection{Methodology}

To take into account the simultaneous contribution of both the number of drops and their size in the variability of $Z-R$ relations, we consider the ratio between these DSDs characteristic parameters. The approach in this work is to find functional relationships between the instant ratio $D_{0} / N_{T}$ (between the median volume diameter and the total number of drops per unit volume for a given rainfall event) and the rain rate $R$ in order to examine the influence on the corresponding $Z-R$ relations. In particular, we attempt to determine possible relations between coefficients of both relationships. Rosenfeld and Ulbrich [23] and more recently papers by Ulbrich and Atlas [36] and Ochou et al. [37] have suggested a set of relations between pairs of rainfall integral parameters. For instance, they proposed power-laws for the pairs integral parameters $D_{0}-R$ and $N_{T}-R$ such as $D_{0}=\varepsilon R^{\delta}$ and $N_{T}=\xi R^{\eta}$. Consequently, such power law relationship would also characterize the relation between parameters $D_{0} / N_{T}$ and $R$. Thus, on the basis of whole or subdivided rainy events (in convective or stratiform region in cases of a squall line) functions fitted to the scatter plots $\left(D_{0} / N_{T}, R\right)$ are power-laws of the form:

$$
D_{0} / N_{T}=\alpha R^{\beta} .
$$

On a log-log scale, the fitted function is a straight line where $\alpha$ corresponds to the value of $D_{0} / N_{T}$ for $R=1$ $\mathrm{mm} \cdot \mathrm{h}^{-1}$, while $\beta$ is the slope of the line. The analogy between the expression (1) and the relation $Z=A R^{b}$ between the reflectivity radar and the rain rate permits to assume the existence of a consistent behavior of the coefficients $A$ and $b$, regarding the coefficients $\alpha$ and $\beta$ respectively. Such an analysis is performed with all the rain events in the database categorized according to different types of precipitation. 

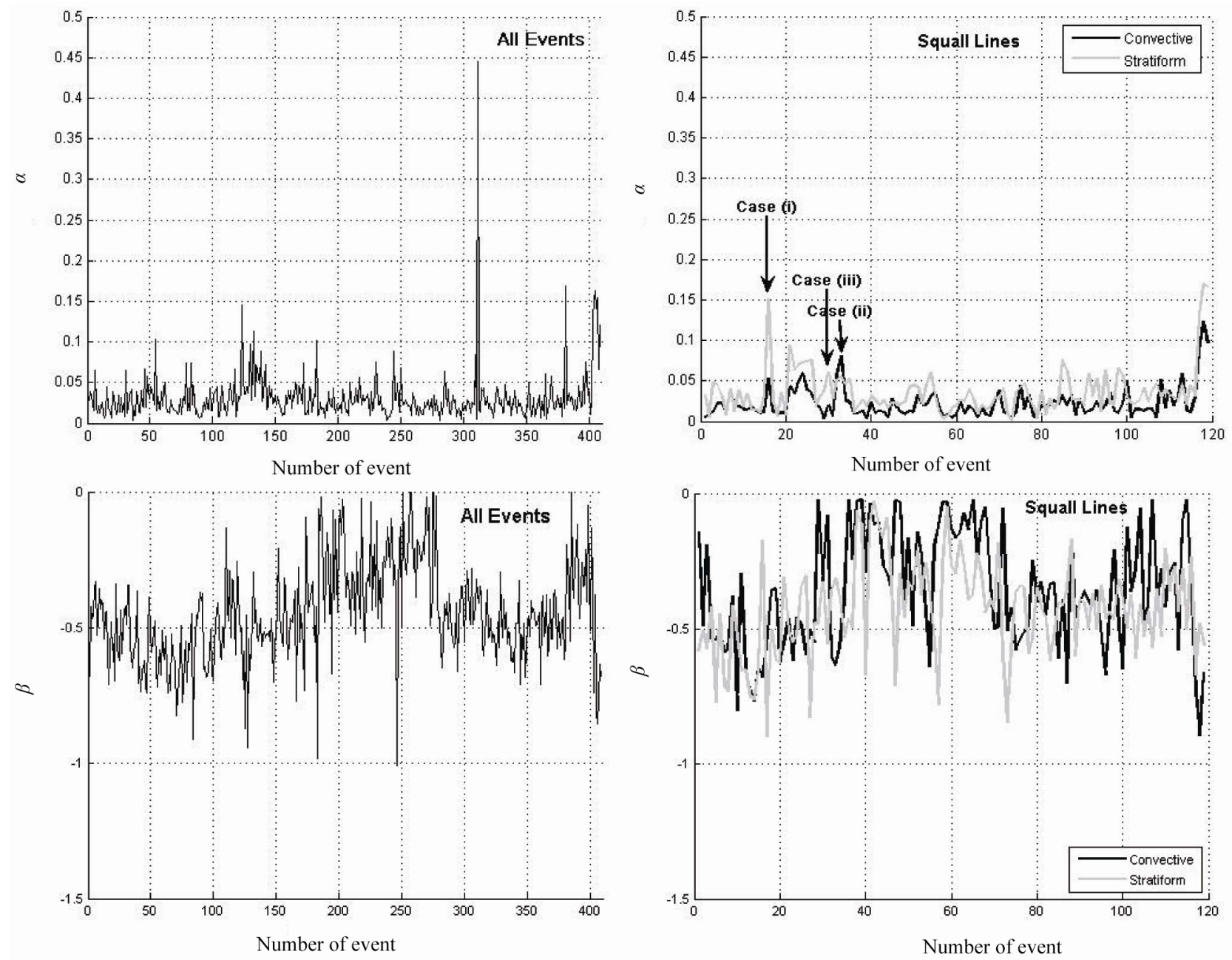

Figure 5. Event basis variation of the $D_{0} / N_{T}-R$ relationship coefficients $\alpha$ and $\beta$ : (a,b) all events irrespective of their nature, (c, d) convective and stratiform parts of squall lines.Case (i), Case (ii), Case (iii) indicate specific cases of convective-stratiform comparison of $\alpha$ and $\beta$ values (see text).

\subsection{Results and Discussion}

Figure 4 shows the scatter plots and the fitted curves in relation to an entire squall line event or the different subdivisions (convective, stratiform) performed on that specific squall line. The results for these specific cases (Figure 4) and all individual events (Figures 5(a) and (b)) show that $D_{0} / N_{T}$ is a decreasing power of $R$ with $\alpha$ $>0$ and $\beta<0$. As expected from analytical expression of $N_{T}-R, D_{0}-R$ power-law proposed by authors $[23,36]$ under hypothesis of positive $\mu$ of a gamma model, the observed exponent $\beta$ of $D_{0} / N_{T}-R$ is negative. In DSD from Africa, admittedly it is rare to find negative values of $\mu$.

The scatter plots and related fitting curves provide different scenarios.For example, considering the coefficients $\alpha$ and $\beta$ which characterize the all studied squall lines events, the convective and stratiform pre- cipitations offer disparate situations illustrated in Figures 5(c) and (d): (case i) $\alpha_{c}<\alpha_{s}$ and $\left|\beta_{c}\right|>\left|\beta_{s}\right|$, (case ii) $\alpha_{c}>\alpha_{s}$ and $\left|\beta_{c}\right|>\left|\beta_{s}\right|$, (case iii) $\alpha_{c}<\alpha_{s}$ and $\left|\beta_{c}\right|<\left|\beta_{s}\right|$ shown in Figure by arrows. The analysis of Figures 3(b), (c) and Figures 5(c), (d) exhibits that for a specific type of rain (stratiform or convective) of a given squall line, two successive events named 1 and 2 are characterized by:

$$
\begin{aligned}
& \alpha_{1}<\alpha_{2} \text { then } A_{1}<A_{2} \text { and vice versa } \\
& \left|\beta_{1}\right|>\left|\beta_{2}\right| \text { then } b_{1}<b_{2} \text { and vice versa. }
\end{aligned}
$$

In addition, this remark should also be noted when the events 1 and 2 are specifically the convective and stratiform region of a given squall line.

The analogy of $Z=A R^{b}$ and $D_{0} / N_{T}=\alpha R^{\beta}$ relationships suggests that the values of $\alpha$ and $\beta$ may vary with those of $A$ and $b$ respectively as confirmed in Figure 6, illustrating the comparison of their respective 
series at the scale of the rainfall event. The analysis of these curves derived from miscellaneous rain events data of different climatic zones shows those variations of $A$ and $\alpha$ on one hand and those of $b$ and $\beta$ on the other
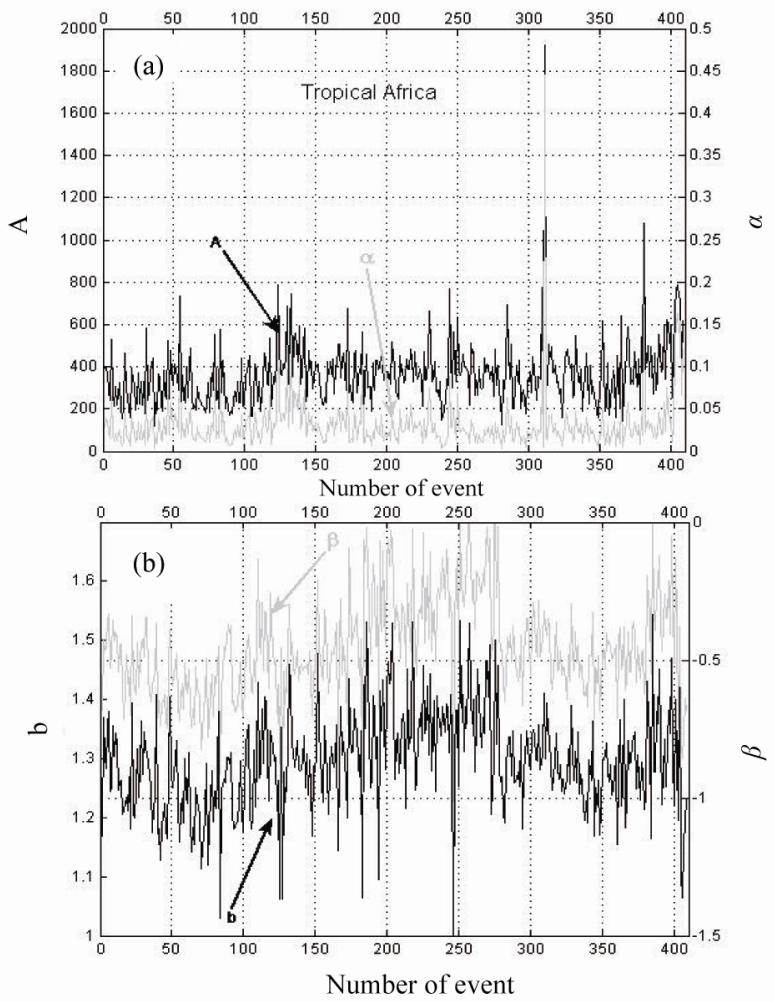

Figure 6. Compared event basis variations of : (a) $A$ and $\alpha$, (b) $b$ and $\beta$.

hand, are remarkably similar: a strong variation of $A$ corresponds to a strong variation of $\alpha$ whereas a small variation of $b$ is associated with a low fluctuation of $\beta$. We propose in following paragraph to determine the functional relationship between $A$ and $\alpha$, then between $b$ and $\beta$.

Figure 7 and Figure 8 show the scatter plots of couples $(A, \alpha)$ and $(b, \beta)$ respectively and the corresponding regression curves. All the samples made with various types of events (squall lines, thunderstorms, widespread stratiform rain) from equatorial, tropical, sahelian and guinean climatic zones, exhibit that the multiplicative factor $A$ of $Z-R$ increases with $\alpha$ while the exponent $b$ decreases with $|\beta|$. As can be seen on the graphs, fitting curves corresponding to each of the relations are of the form:

$$
\begin{array}{r}
A=a_{1} \alpha^{a_{2}}, \text { with } \alpha>0 \\
b=b_{1} \beta+b_{2}, \text { with } \beta<0
\end{array}
$$

The strong correlation coefficients greater than 0.80 demonstrates the close relationships existing between the
Table 3. Coefficients of the relationship $A=a_{1} \alpha^{a_{2}}$ et $b=$ $b_{1} \beta+b_{2}$ for different types of précipitations.

\begin{tabular}{ccccc}
\hline \multirow{2}{*}{ Rain types } & \multicolumn{4}{c}{ Relationships } \\
\cline { 2 - 5 } & $a_{1}$ & $a_{2}$ & $b_{1} \alpha^{a_{2}}$ & $b_{2}$ \\
\cline { 2 - 5 } & 2172.9 & 0.486 & 0.4 & 1.46 \\
& 1996.9 & 0.468 & 0.4 & 1.45 \\
Squall lines (SL) & \multicolumn{4}{c}{$\beta+b_{2}$} \\
Convective (SL) & 2332.6 & 0.499 & 0.5 & 1.52 \\
Stratiform (SL) & 2187.8 & 0.508 & 0.4 & 1.49 \\
Storms events & 2448.8 & 0.521 & 0.5 & 1.53 \\
Stratiform events & 2273.7 & 0.510 & 0.4 & 1.49 \\
All events & 2235.5 & 0.499 & 0.43 & 1.49 \\
Mean & 154.60 & 0.019 & 0.0516 & 0.0316 \\
$\sigma$ & 0.069 & 0.04 & 0.12 & 0.02 \\
cv & \multicolumn{4}{c}{}
\end{tabular}

multiplicative factors $A$ and $\alpha$ and exponents $b$ and $\beta$ respectively. The quasi-similarity of functional relationships obtained (listed in Table 3) using categorizing samples of different rainfall events such as squall lines and their convective and stratiform regions, thunderstorms, widespread continuous light rain (stratiform rain), taken from different latitudes, may be regarded as quasi universal and thus applicable to other rain event samples. The coefficients of variation $(\mathrm{CV})$ of $a_{1}, a_{2}, b_{1}$ and $b_{2}$ parameters, lower than $15 \%$ (Table 3) confirm the almost constant character of those relations (2) and (3). The unique relations should be of the form:

$$
\begin{aligned}
& A=2235.5 \alpha^{0.499} \\
& b=0.43 \beta+1.49
\end{aligned}
$$

where the respective coefficients are the mean values of individual ones derived from categorized precipitation types (Table 3).

To emphasize the effect of the combination of $N_{T}$ and $D_{0}$ on the variability of $Z-R$ relations through the coefficients $A$ and $b$, we proposed to investigate the functional relationships $A=f(\varepsilon)$ and $b=f(\delta)$ then $A=f(\xi)$ and $b=f(\eta)$ concerning the relationships $Z=A R^{b}$, $D_{0}=\varepsilon R^{\delta}$ and $N_{T}=\xi R^{\eta}$.

This approach aims to show how $A$ and $b$ behave in relation to the multiplicative factors $(\varepsilon, \xi)$ and exponents $(\delta, \eta)$ of $D_{0}$ and $N_{T}$ separately in their relationship with the rainfall rate $R$.

Figure 9 and Figure 10 present the scatter plots for only convective and stratiform samples from squall lines. Table 4 gathers the results for the six (6) samples studied previously. Their comparison shows an uneven behavior in the case of relations obtained with $N_{T}$, while $D_{0}$ behaves consistently (almost identical relations) as in the case of the ratio $D_{0} / N_{T}$, whatever the type of rain. Indeed, in the case of $N_{T}-R$ relation, we find sharp distinctive relations between convective $\left(A=2981.6 \xi^{0.54} ; b=\right.$ $-0.48 \eta+1.55)$ and stratiform $\left(A=5698.6 \xi^{0.63} ; b=\right.$ $-0.60 \eta+1.65)$ sampled regions of squall lines. In addi- 

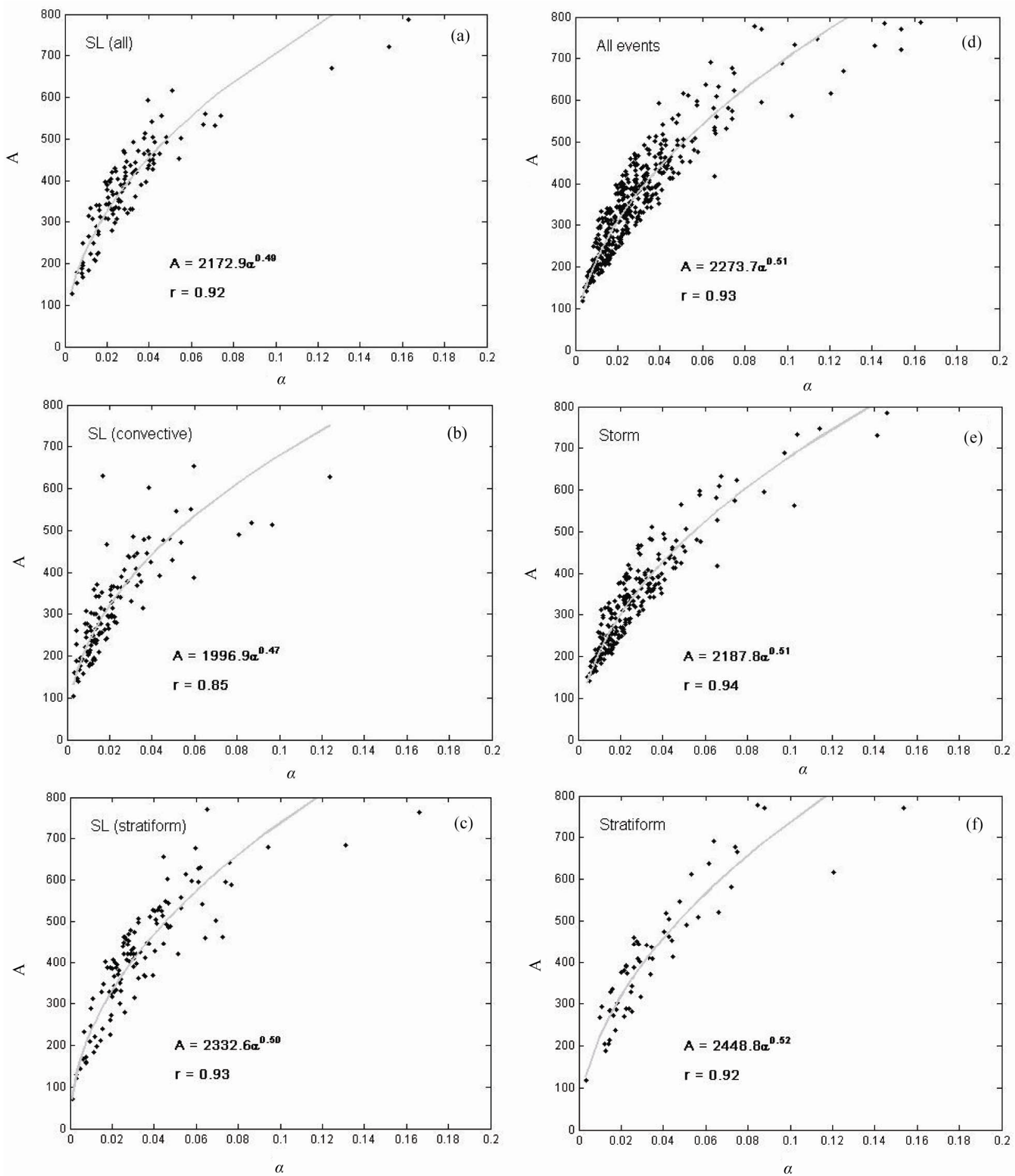

Figure 7. Relationship between the $Z-R$ coefficient $A$ and the $D_{0} / N_{T}-R$ coefficient $\alpha$ : (a) combination of squall lines, (b) convective parts of squall lines, (c) stratiform parts of squall lines, (d) all rainfall systems, (e) storm water, (f) stratiform rain.

tion, the coefficient of variation in case of multiplicative factors of $A-\xi$ relative to $N_{T}$ is higher $(16 \%)$ than in the cases of $A-\varepsilon(4 \%)$ for $D_{0}$, and $A-\alpha(7 \%)$ corresponding to the combination $D_{0} / N_{T}$.
Given the fact that $Z$ and $R$ both depend on the drops size and number, this result shows that taking them into account separately is not sufficient to explain the variability of $A$ and $b$ coefficients of $Z-R$ relationship. Fur- 

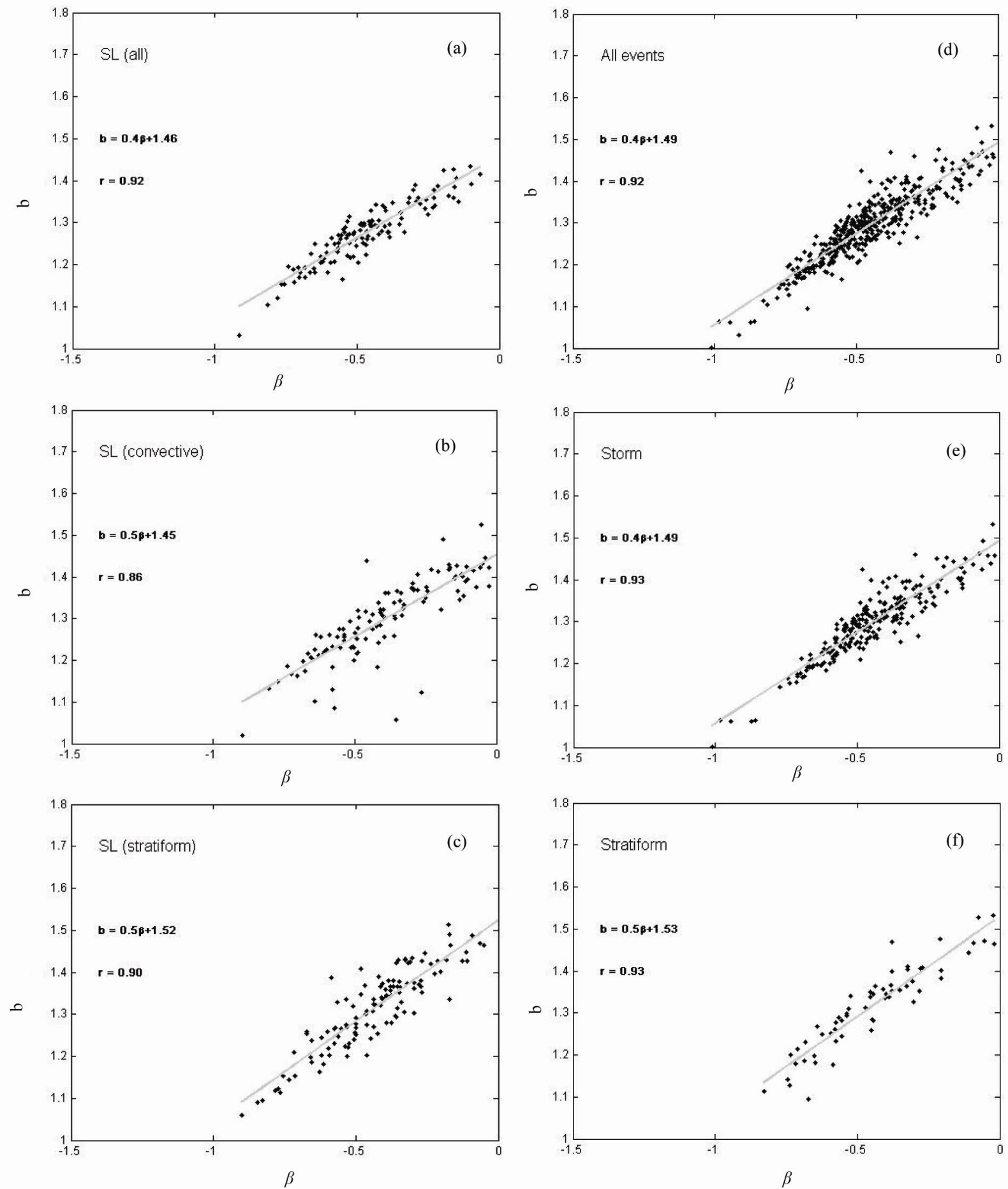

Figure 8. Relationship between the coefficients $b$ and $\beta$ of $D_{0} / \mathbf{N}_{\mathrm{T}}-\mathrm{R} Z-R$ respectively: (a) combination of squall lines, (b) convective part of squall lines, (c) stratiform part of squall lines, (d) all rainfall systems, (e) stormy rain events, (f) stratiform rain events.

thermore, it shows that their variability is much more dependent on the raindrops number (represented by $N_{T}$ ) than the size (represented by $D_{0}$ ).

These results reasonably confirm that the $Z-R$ rela- tionships disparity and variability are not as random as it seems, but depend closely on the precipitation intrinsic characteristics such as the raindrops size and number, taken into account here by $\alpha$ and $\beta$ coefficients of 

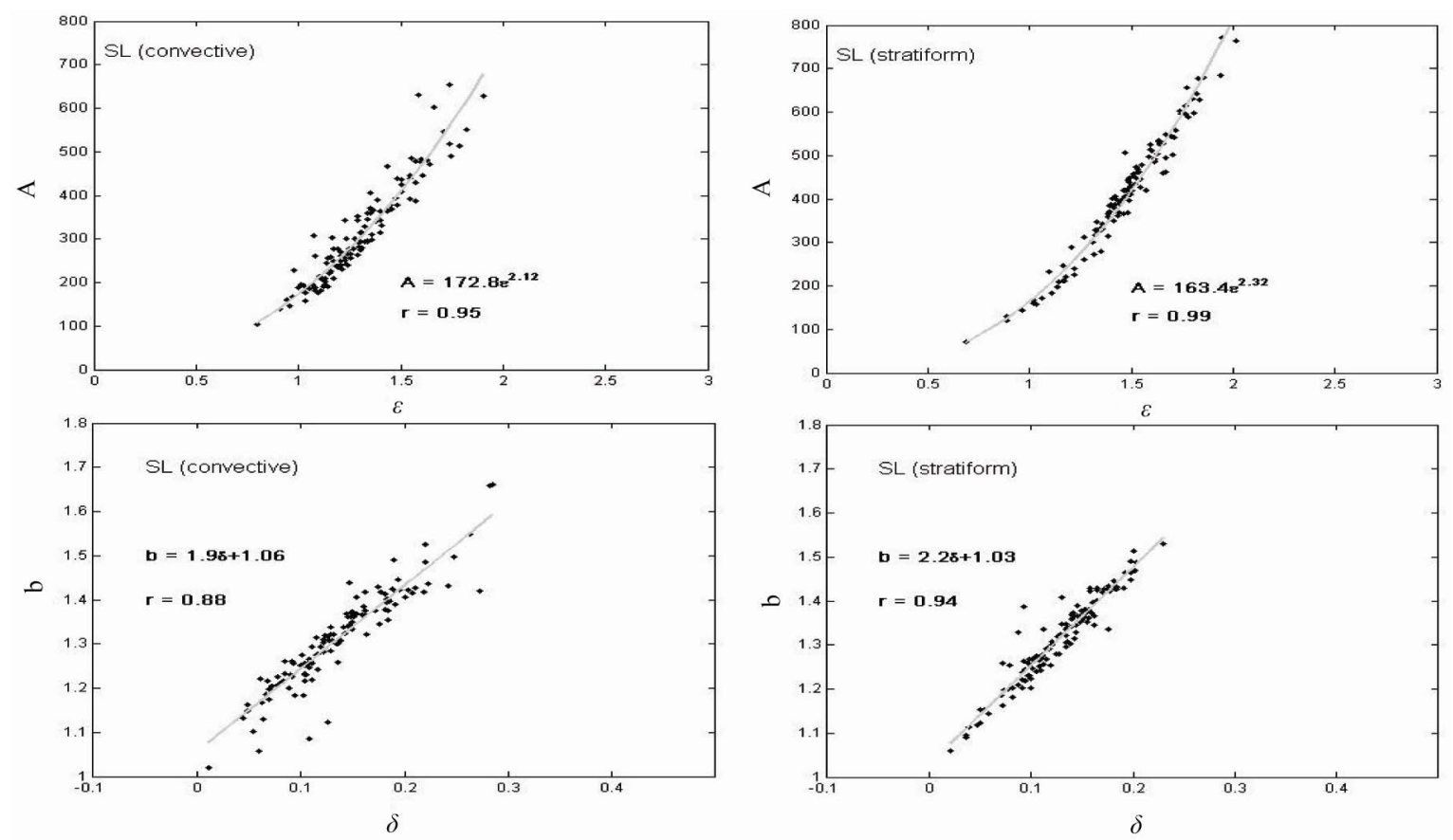

Figure 9. Relationship between the coefficients $A$ and $\varepsilon$, the exponents $b$ and $\delta$ of $D_{0}-R$ and $Z-R$ respectively for convective and stratiform rainfall type derived from all the squall lines.
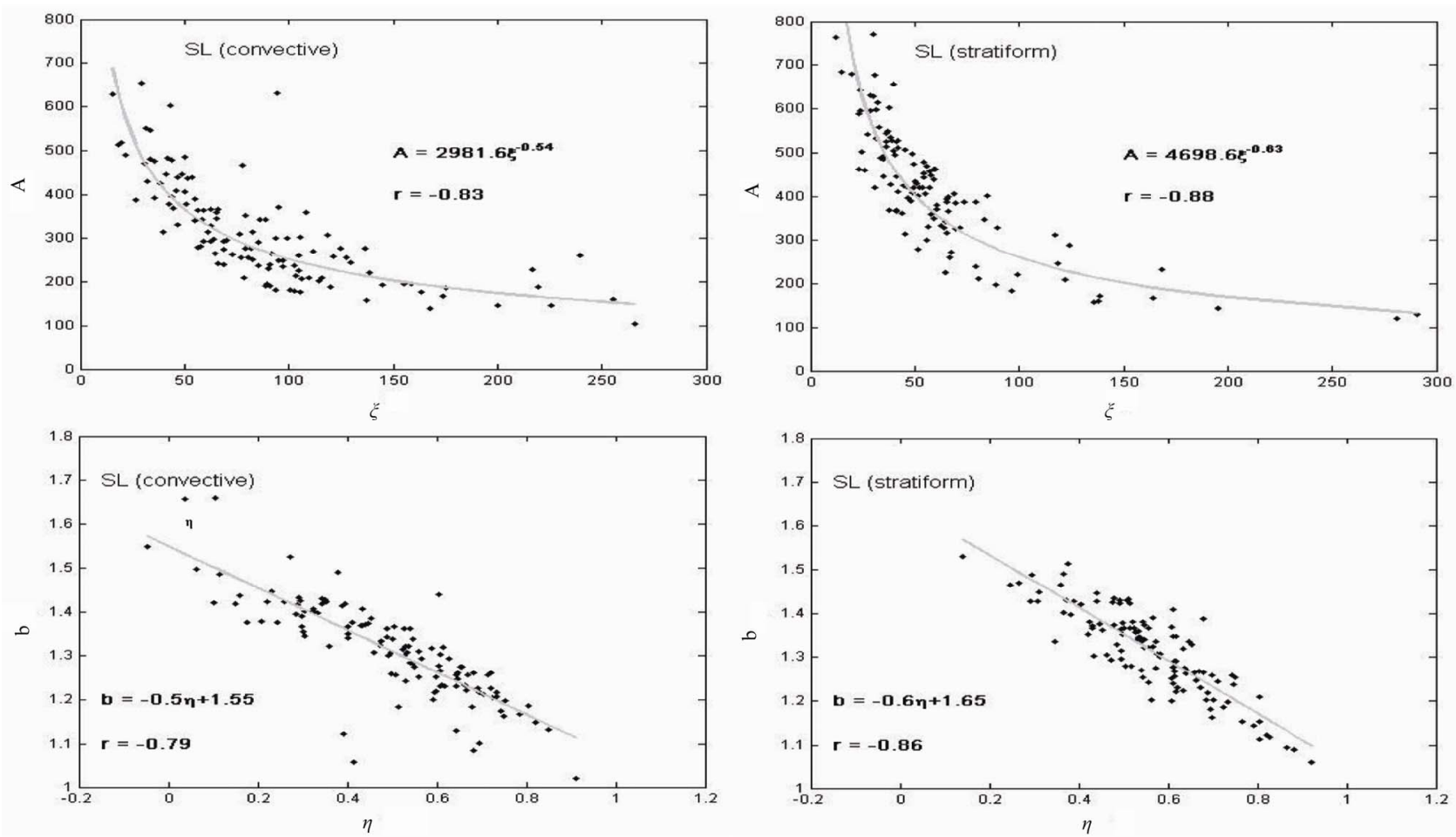

Figure 10. Relationship between the coefficients $A$ and $\xi$, the exponents $b$ and $\eta$ of $N_{T}-R$ and $Z-R$ respectively for convective and stratiform rainfall type derived from all the squall lines.

the $D_{0} / N_{T}-R$ relationship.

Another important aspect inferred from these relationships is that they allow to understand that squall lines stratiform region may have a coefficient $A_{s}$ greater than the coefficient $A_{c}$ of the convective region $\left(A_{s}>A_{c}\right)$ when the corresponding coefficients $\alpha$ are such as 
Table 4. Coefficients of the relationships $A=f(x)$ and $b=f(y)$ where $x$ is the multiplicative factor and $y$ the exponent of the relationships between $R$ and the parameters $D_{0} / N_{T}, D_{0}$ and $N_{T}$ for different types of precipitations.

\begin{tabular}{|c|c|c|c|c|c|c|c|c|c|c|c|c|}
\hline \multirow{4}{*}{ Rain types } & \multicolumn{4}{|c|}{ Relationships } & \multicolumn{4}{|c|}{ Relationships } & \multirow{2}{*}{\multicolumn{4}{|c|}{$\begin{array}{c}\text { Relationships } \\
N_{T}=\xi R^{\eta}\end{array}$}} \\
\hline & \multicolumn{4}{|c|}{$D_{0} / N_{T}=\alpha R^{\beta}$} & \multicolumn{4}{|c|}{$D_{0}=\varepsilon \mathrm{R}^{\delta}$} & & & & \\
\hline & \multicolumn{2}{|c|}{$A=a_{1} \alpha^{a_{2}}$} & \multicolumn{2}{|c|}{$b=b_{1} \beta+b_{2}$} & \multicolumn{2}{|c|}{$A=c_{1} \varepsilon^{c_{2}}$} & \multicolumn{2}{|c|}{$b=d_{1} \delta+d_{2}$} & \multicolumn{2}{|c|}{$A=e_{1} \xi^{e_{2}}$} & \multicolumn{2}{|c|}{$b=f_{1} \eta+f_{2}$} \\
\hline & $a_{1}$ & $\mathrm{a}_{2}$ & $\mathrm{~b}_{1}$ & $\mathrm{~b}_{2}$ & $\mathrm{c}_{1}$ & $\mathrm{c}_{2}$ & $\mathrm{~d}_{1}$ & $\mathrm{~d}_{2}$ & $\mathrm{e}_{1}$ & $\mathrm{e}_{2}$ & $\mathrm{f}_{1}$ & $\mathrm{f}_{2}$ \\
\hline Squall lines (SL) & 2172.9 & 0.486 & 0.4 & 1.46 & 161.5 & 2.338 & 2.062 & 1.040 & 4013.2 & -0.596 & -0.474 & 1.552 \\
\hline Convective (SL) & 1996.9 & 0.468 & 0.4 & 1.45 & 172.8 & 2.122 & 1.883 & 1.055 & 2981.6 & -0.536 & -0.479 & 1.549 \\
\hline Stratiform (SL) & 2332.6 & 0.499 & 0.5 & 1.52 & 163.4 & 2.317 & 2.231 & 1.029 & 4698.6 & -0.628 & -0.602 & 1.653 \\
\hline Storms events & 2187.8 & 0.508 & 0.4 & 1.49 & 157.2 & 2.324 & 2.204 & 1.027 & 4344.4 & -0.638 & -0.534 & 1.602 \\
\hline Stratiform events & 2448.8 & 0.521 & 0.5 & 1.53 & 158.3 & 2.367 & 2.227 & 1.033 & 4935.5 & -0.650 & -0.597 & 1.659 \\
\hline All events & 2273.7 & 0.510 & 0.4 & 1.49 & 158.0 & 2.346 & 2.189 & 1.030 & 4489.8 & -0.637 & -0.534 & 1.601 \\
\hline Mean & 2235.5 & 0.499 & 0.43 & 1.49 & 161.9 & 2.302 & 2.133 & 1.036 & 4234.8 & -0.614 & -0.537 & 1.603 \\
\hline$\sigma$ & 154.60 & 0.019 & 0.0516 & 0.0316 & 5.86 & 0.0901 & 0.137 & 0.011 & 693.1 & 0.042 & 0.055 & 0.047 \\
\hline $\mathrm{cV}$ & 0.069 & 0.04 & 0.12 & 0.02 & 0.036 & 0.039 & 0.064 & 0.010 & 0.163 & -0.069 & -0.103 & 0.030 \\
\hline
\end{tabular}

$\alpha_{s}>\alpha_{c}$. Similarly, if both regions are such as $\alpha_{s}<\alpha_{c}$, we will then have $A_{s}<A_{c}$. These two situations are quite possible since it depends on the simultaneous behavior of the raindrops size and number in distinctive regions of the squall line, taken in account through the ratio $D_{0} / N_{T}$ in this work. Indeed, if a stratiform part of a given squall line is characterized by large but few drops (high $D_{0}$, small $N_{T}$ ), the ratio $D_{0} / N_{T}$ will be higher than in the convective part which is characterized by large but more numerous drops (high $D_{0}$, high $N_{T}$ ) providing lower $D_{0} / N_{T}$ ratios. The radar reflectivity factor $Z$ depending on the $6^{\text {th }}$ power of the diameter, remains relatively high in the stratiform region where $R$, which depends on the $3^{\text {rd }}$ power of the diameter, is very weak. Because of the high values of $Z$ in this part, the relationship $Z=A_{s} R^{b_{s}}$ is such as $A_{s}$ ( $Z$ value for $\left.R=1 \mathrm{~mm} \cdot \mathrm{h}^{-1}\right)$ must be high enough to "compensate" for low values of $R$. On the other hand, in the convective part where $Z$ and $R$ are characterized by high values, the coefficient $A_{c}$, although high, remains very often lower than $A_{s}\left(A_{s}>A_{c}\right)$. Conversely if a squall line's stratiform region is such as low rain rates are due to small but more numerous drops (small $D_{0}$, high $N_{T}$ )-yielding a low $D_{0} / N_{T}$ ratio valuethe radar reflectivity factor $Z$ is low as well as the rain rate $R$. Both parameters varying in the same sense, the relationship $Z=A_{s} R^{b_{s}}$ in this part is such as $A_{s}$ would be logically low. In the corresponding convective region, because of high $D_{0}$ and high $N_{T}$, the ratio $D_{0} / N_{T}$, although low, remains higher than in the stratiform region. The $Z-R$ coefficient $A_{c}$ would be then higher than $A_{s}$ of the stratiform region $\left(A_{s}<A_{c}\right)$. These two situations described above are fairly well illustrated by the squall lines rainfall events observed respectively on 17 October 1987 in Abidjan (Côte d'Ivoire) marked by $A_{s}>A_{c}$ and on $1^{\text {st }}$ July 1988 in Boyele (Congo) where on the contrary we have $A_{s}<A_{c}$ (Figure 11).

\section{Conceptual Schematization of Possible Situations}

The $Z-R$ relationships, being characterized simultaneously by the coefficients $A$ and $b$, their respective behaviors with respect to $\alpha$ and $\beta$ suggests several possible combinations existing in the precipitations. In this section we propose a schematization of different situations that justify and allow understanding the great disparity of the $Z-R$ relationships in the precipitations. To do this, consider two rainfall events indexed 1 and 2 which can be independent rainfall events or convective and stratiform regions of the same event (case of squall lines). Let us assume a particular situation where the relations $D_{0} / N_{T}=\alpha R^{\beta}$ are such as the slopes $\beta$ are identical $\left(\beta_{1}=\beta_{2}=\beta\right)$ and the multiplicative factors (the intercept in log-log scale) are different $\left(\alpha_{1} \neq \alpha_{2}\right)$. We have thus the following relations:

$$
\begin{gathered}
D_{0} / N_{T}=\alpha_{1} R^{\beta} \Rightarrow Z=A_{1} R^{b} \\
D_{0} / N_{T}=\alpha_{2} R^{\beta} \Rightarrow Z=A_{2} R^{b}
\end{gathered}
$$

There are two corresponding possibilities named $P_{1}$ and $P_{2}$ shown schematically in Figures 12(a) and (c) in a log-log scale.

Let us now suppose another particular situation where relations $D_{0} / N_{T}=\alpha R^{\beta}$ are such as the multiplicative factors are identical $\left(\alpha_{1}=\alpha_{2}=\alpha\right)$ and the slopes different $\left(\beta_{1} \neq \beta_{2}\right)$. We therefore have the following relations:

$$
\begin{aligned}
& D_{0} / N_{T}=\alpha R^{\beta_{1}} \Rightarrow Z=A R^{b_{1}} \\
& D_{0} / N_{T}=\alpha R^{\beta_{2}} \Rightarrow Z=A R^{b_{2}}
\end{aligned}
$$

which also refer to two possibilities $P_{1}^{\prime}$ and $P_{2}^{\prime}$ represented schematically in Figures 12(b) and (d).

However, it should be noted that the situations described above are particular cases rarely observed. In- 

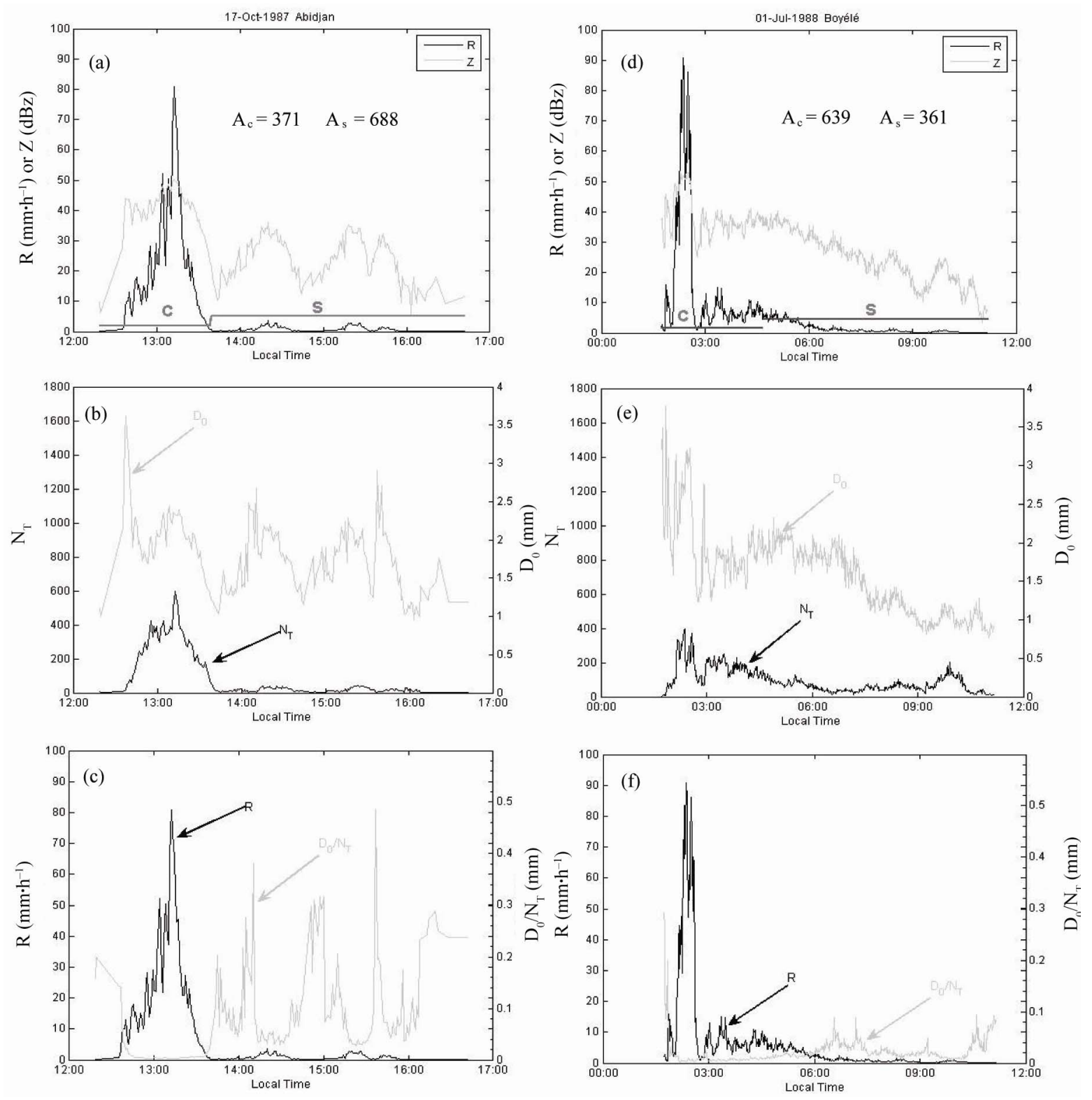

Figure 11. Time series of the rain rate $R$, the reflectivity factor $Z$, the raindrops number $N_{T}$, the mean volume diameter $D_{0}$ and their ratio $D_{0} / N_{T}$ for two rainfall events observed in Abidjan ((a)-(c)) and Boyele ((d)-(f)).

deed, given the high variability of the raindrops size and number in the precipitations, it is uncommon to see two independent events and especially the convective and stratiform regions of a single rainfall event, be characterized by relations $Z-R$ having the same multiplicative factor $A$ or the same exponent $b$. In the observed precipitations, different parts of a rain event are characterized by a common area (mixing) especially in low and moderate rain rates, so that the intercepts $(A$ or $\alpha)$ and slopes $(b$ or $\beta)$ undergo more or less strong changes depending

On the degree of mixing and the raindrops number and size in attendance, the actual situations are therefore described by, the combinations $\left(P_{1}+P_{1}^{\prime}\right),\left(P_{1}+P_{2}^{\prime}\right)$, $\left(P_{2}+P_{1}^{\prime}\right)$ and $\left(P_{2}+P_{2}^{\prime}\right)$, represented in Figure 13 . These situations occur in the rainfall events observed in this study. They show the great variability of $Z-R$ relationships within a single rainfall event and between independent events. Thus, in the case where samples 1 and 2 represent the convective and stratiform regions of a squall line, this analysis gives the reasons why Yuter and Houze [17] found that the coefficient $A$ in the convective part is higher than that of the stratiform part $\left(A_{c}>A_{s}\right)$ and those for which, Tokay and Short [5], conversely, obtained $A_{c}<$ 

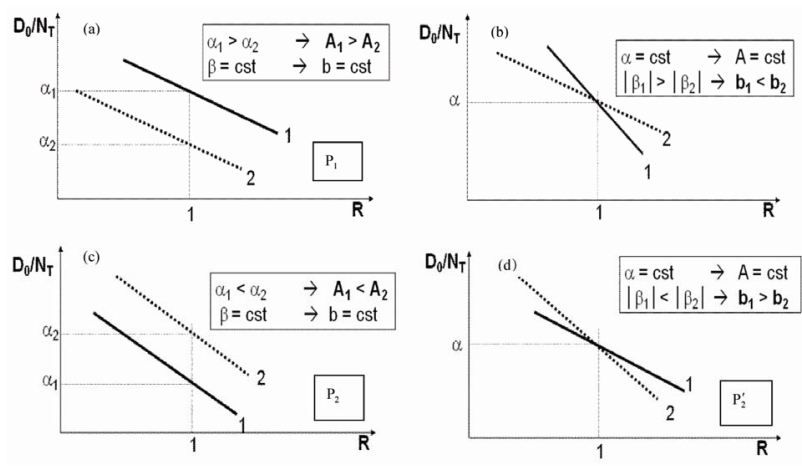

Figure 12. Conceptual schematization of specific situations in observed rainfall events to understand the variability of $Z-R$ relationships.
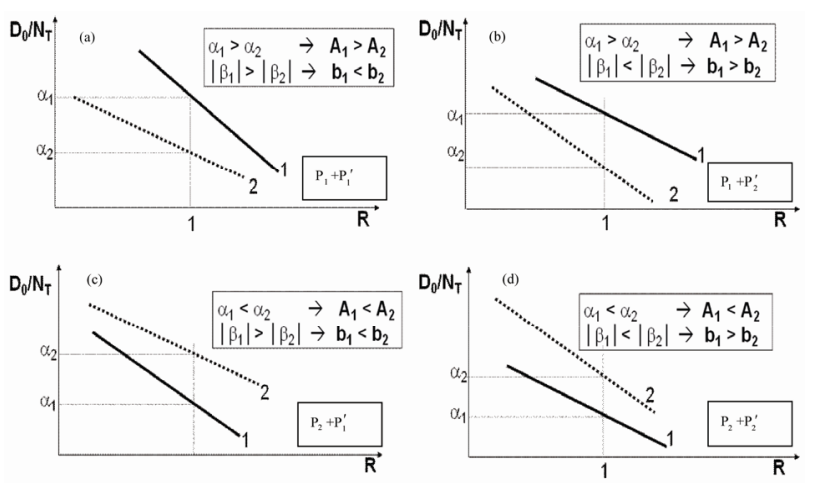

Figure 13. Conceptual schematization of possible actual situations showing $Z-R$ relationships variability in observed rainfall events.

$A_{s}$. In fact, their respective results are shown for the former by the situations $\left(P_{1}+P_{1}^{\prime}\right)$ or $\left(P_{1}+P_{2}^{\prime}\right)$ and for the latter by the situations $\left(P_{2}+P_{1}^{\prime}\right)$ or $\left(P_{2}+P_{2}^{\prime}\right)$. Each of these situations may exist predominantly in a climatic zone with its own characteristics; we can therefore understand the two trends as well as the high variability and the disparity of $Z-R$ relationships. These results suggest us not directly assign categories of $Z-R$ relationships to precipitation types called 'convective' and 'stratiform' considering the only rain rates which do not always reflect the precipitating system intrinsic characteristics, but to take into account simultaneously the drops size and number. For example, using radar obervations, Yuter and Houze [17] showed that the stratiform region characteristics of a squall line depend on the degree and nature of dynamic and thermo-dynamic processes prevailing in the convective part.Thus, taking into account only drops diameters as Atlas et al. [19] and Tokay and Short [5] did or the only drops number $[18,30]$, is not sufficient to discrimi nate precipitation. From ground-based measurements, the simultaneous consideration of both characteristic parameters of the DSD, which are the raindrops number and size, allow to better understand the reasons of the $Z-R$ relationships variability in the precipitations.

\section{Conclusions}

The variability of the relationship between the rain rate $R$ and the radar reflectivity factor $Z$, useful in estimating rainfall by radar, has been a major concern in this work.

The study of relationships in independent rainfall events confirmed their great variability from a given precipitation to another and within the same precipitation type. Based on a sampling of whole and/or subdivided events, it appeared that the convective (indexed $c$ ) and stratiform (indexed $s$ ) regions of squall lines are characterized by multiplicative factors such as $A_{c}>A_{s}$ or $A_{c}<$ $A_{s}$ as well as exponents such as $b_{c}>b_{s}$ or $b_{c}<b_{s}$. The analysis of the rain drops size and number, respectively indicated by $D_{0}$ and $N_{T}$, showed that the behavior of $Z-R$ relationships is primarily due to their combined effect.

This contribution of both DSD integral parameters has been taken into account considering their ratio $D_{0} / N_{T}$. The comparative study of $Z-R$ relationship and $D_{0} / N_{T}=\alpha R^{\beta}(\beta<0)$ showed a consistent behavior of the coefficients $A$ and $b$ compared to the coefficients $\alpha$ and $\beta$ respectively. Indeed, this study achieved with samples of different types whole events or subdivided into convective/stratiform regions (in case of squall lines), at all observation sites put together, allowed to reveal relationships almost similar and independent of the precipitation nature. It has been established that $A$ and $b$ are power and linear functions of $\alpha$ and $\beta$ respectively, such as $A=2235.5 \alpha^{0.499}$ and $b=0.43 \beta+1.49$. This result, obtained with different types of precipitation, shows that taking into account the raindrops size and number through the simple ratio $D_{0} / N_{T}$ enable to predict how the $Z-R$ relationship coefficients $A$ and $b$ may vary in rain events. It has been also shown that their variability is much more dependent on the raindrops number than the size. In addition, while showing the non-random variability of the $Z-R$ relationships, these results allow us to understand that the convective region of a squall line may have a coefficient $A$ higher or lower than the stratiform region. We so understand that the work of the 'school $A_{c}>A_{s}$ ' [17] and those of the 'school $A_{c}<A_{s}$ ' [5] are not contradictory, their results being probably related to precipitations with different physical characteristics.

We conclude that in a future study, we can use the combination of rain drop size and number to attempt a differentiation between stratiform and convective precipitation since Heinrich et al. [35] have shown clear evidence of a relationship between riming processes (an indication of updrafts and convection) and raindrop 
spectra's intrinsic integrated parameters namely the intercept parameter $N_{0}$ of an exponential model fitting observed DSD and the median volume diameter, $D_{0}$.

\section{Acknowledgements}

The authors are grateful to all of those who contributed to the data set used in this study. Greatly appreciated are the advice, detailed comments on the manuscript and discussions with Prof. Henri Sauvageot. We are also grateful to the PASRES for their financial contribution.

\section{References}

[1] J. S. Marshall and W. M. K. Palmer, "The Distribution of Raindrops with Size," Journal of Meteorology, Vol. 5, No. 51948, pp. 165-166.

doi:10.1175/1520-0469(1948)005<0165:TDORWS $>2.0$. $\underline{\mathrm{CO} ; 2}$

[2] J. Joss and A. Waldvogel, "Raindrop Size Distribution and Doppler Velocities," Proceedings of the 14th Radar Meteorology Conference, Boston, 1970, pp. 153-156.

[3] P. T. Willis, "Functional Fit to Some Observed Drop Size Distributions and Parameterization of Rain," Journal of the Atmospheric Sciences, Vol. 41, No. 9, 1984, pp. 1648-1661.

doi:10.1175/1520-0469(1984)041<1648:FFTSOD $>2.0 . C$ $\underline{\mathrm{O} ; 2}$

[4] H. Sauvageot and J. P. Lacaux, "The Shape of Averaged Drop Size Distributions," Journal of the Atmospheric Sciences, Vol. 52, No. 8, 1995, pp. 1070-1083. doi:10.1175/1520-0469(1995)052<1070:TSOADS $>2.0 . \mathrm{C}$ $\underline{\mathrm{O} ; 2}$

[5] A. Tokay and D. A. Short, "Convective vs Stratiform Rain in the West Pacific during TOGA COARE: Evidence from Raindrop Spectra," Journal of Applied Meteorology, Vol. 35, No. 3, 1996, pp. 355-371.

doi: $10.1175 / 1520-0450(2001) 040<1118:$ TCONDT $>2.0 . C$ $\underline{\mathrm{O} ; 2}$

[6] J. Testud, S. Oury, R. A. Black, P. Amayenc and X. Dou, "The Concept of Normalized Distribution to Describe Raindrop Spectra: A Tool for Cloud Physics and Cloud Remote Sensing," Journal of Applied Meteorology, Vol. 40, No. 6, 2001, pp. 1118-1140.

doi:10.1175/1520-0450(2001)040<1118:TCONDT $>2.0 . \mathrm{C}$ $\underline{\mathrm{O} ; 2}$

[7] M. Maki, T. D. Keenam, Y. Sasaki and K. Nakamura, "Characteristics of the Raindrop Size Distribution in Tropical Continental Squall Lines Observed in Darwin, Australia," Journal of Applied Meteorology, Vol. 40, No. 8, 2001, pp. 1393-1412. doi:10.1175/1520-0450(2001)040<1393:COTRSD $>2.0 . C$ $\underline{\mathrm{O} ; 2}$

[8] R. Uijlenhoet, J. A. Smith and M. Steiner, "The Microphysical Structure of Extreme Precipitation as Inferred from Ground-Based Raindrop Spectra," Journal of the Atmospheric Sciences, Vol. 60, No. 10, 2003, pp. 1220-
1238.

doi:10.1175/1520-0469(2003)60<1220:TMSOEP $>2.0$.C $\underline{\mathrm{O} ; 2}$

[9] R. Uijlenhoet, M. Steiner and J. A. Smith, "Variability of Raindrop Size Distributions in a Squall Line and Implications for Radar Rainfall Estimation," Journal of Hydrometeorology, Vol. 4, No. 1, 2003, pp. 43-61. doi:10.1175/1525-7541(2003)004<0043:VORSDI $>2.0$.C $\underline{\mathrm{O} ; 2}$

[10] G. W. Lee and I. Zawadzki, "Variability of drop size distributions: Time-Scale Dependence of the Variability and its Effects on Rain Estimation," Journal of Applied Meteorology, Vol. 44, No. 2, 2005, pp. 241-255. doi:10.1175/JAM2183.1

[11] A. Nzeukou, H. Sauvageot, A. D. Ochou and C. M. F. Kebe, "Raindrop Size Distribution and Radar Parameters at Cape Verde," Journal of Applied Meteorology, Vol. 43, No. 1, 2004, pp. 90-105. doi:10.1175/1520-0450(2004)043<0090:RSDARP $>2.0 . C$ $\underline{\mathrm{O} ; 2}$

[12] S. Moumouni, M. Gosset, E. Houngninou, "Main Features of Rain Drop Size Distributions Observed in Benin, West Africa, with Optical Disdrometers," Geophysical Research Letters, Vol. 35, 2008, L23807. doi:10.1029/2008GL035755

[13] L. J. Battan, "Radar Observation of the Atmosphere," University of Chicago Press, Chicago, 1973.

[14] B. Russell, E. R. Williams, M. Gosset, F. Cazenave, L. Descroix, N. Guy, T. Lebel, A. Ali, F. Metayer and G. Quantin, "Radar Rain-Gauge Comparisons on Squall Lines in Niamey, Niger for the AMMA," Quarterly Journal of the Royal Meteorological Society, Vol. 136, No. S1, 2010, pp. 290-304. doi:10.1002/qi.548

[15] A. D. Ochou, "Variabilité Spatio-Temporelle des Moments Statistiques des Distributions des Gouttes de Pluie et Conséquences sur la Mesure des Précipitations par Télédétection Micro-Ondes," Ph.D. Dissertation, Université Cocody-Abidjan, Abidjan, 2003.

[16] M. Steiner, J. A. Smith and R. Uijlenhoet, "A Microphysical Interpretation of Radar Reflectivity-Rain Rate Relationships," Journal of the Atmospheric Sciences, Vol. 61, No. 10, 2004, pp. 1114-1131. doi:10.1175/1520-0469(2004)061<1114:AMIORR $>2.0 . C$ $\underline{\mathrm{O} ; 2}$

[17] S. E. Yuter and R. A. Houze, "Measurements of Raindrop Size Distribution over the Pacific Warm Pool and Implementations for Z-R Relations," Journal of Applied Meteorology, Vol. 36, No. 7, 1997, pp. 847-867. doi:10.1175/1520-0450(1997)036<0847:MORSDO >2.0. $\underline{\mathrm{CO} ; 2}$

[18] A. Tokay, D. A. Short, C. R. Williams, W. L. Ecklund and K. S. Gage, "Tropical Rainfall Associated with Convective and Stratiform Clouds: Intercomparison of Disdrometer and Profiler Measurements," Journal of Applied Meteorology, Vol. 38, No. 3, 1999, pp. 302-320. doi:10.1175/1520-0450(1999)038<0302:TRAWCA $>2.0$. $\underline{\mathrm{CO} ; 2}$

[19] D. Atlas, C. W. Ulbrich, F. D. Marks Jr., E. Amitai and C. R. Williams, "Systematic Variation of Drop Size and 
Radar-Rainfall Relations," Journal of Geophysical Research, Vol. 104, No. D6, 1999, pp. 6155-6169.

doi:10.1029/1998JD200098

[20] D. Atlas, C. W. Ulbrich, F. D. Marks Jr., R. A. Black, E. Amitai, P. T. Willis and C. E. Samsury, "Partitioning Tropical Oceanic Convective and Stratiform Rains by Draft Strength," Journal of Geophysical Research, Vol. 105, No. D2, 2000, pp. 2259-2267. doi:10.1029/1999JD901009

[21] C. W. Ulbrich and D. Atlas, "On the Separation of Tropical Convective and Stratiform Rains," Journal of Applied Meteorology, Vol. 41, No. 2, 2002, pp. 188-195. doi:10.1175/1520-0450(2002)041<0188:OTSOTC $>2.0 . \mathrm{C}$ $\mathrm{O} ; 2$

[22] T. Narayana Rao, D. Narayana Rao and K. Mohan, "Classification of Tropical Precipitating Systems and Associated Z-R Relationships," Journal of Geophysical Research, Vol. 104, 2001, pp. 17699-17711.

[23] D. Rosenfeld and C. W. Ulbrich, "Cloud Microphysical Properties, Processes, and Rainfall Estimation Opportunities. Radar and Atmospheric Science: A Collection of Essays in Honor of David Atlas," Meteorological Monographs, the American Meteorological Society, Boston, No. 52, 2003, pp. 237-258.

[24] J. W. F. Goddard and S.M. Cherry, "The Ability of Dual Polarization Radar (Co-Polar Linear) to Predict Rainfall Rate and Microwave Attenuation," Radio Science, Vol. 19, No. 1, 1984, pp. 201-208. doi:10.1029/RS019i001p00201

[25] N. Balakrishnan, D. S. Zrnic, J. Goldhirsh and J. Rowland, "Comparison of Simulated Rain Rate from Disdrometer Data Employing Polarimetric Radar Algorithms," Journal of Atmospheric and Oceanic Technology, Vol. 6, No. 3, 1989, pp. 476-486. doi:10.1175/1520-0426(1989)006<0476:COSRRF $>2.0 . C$ $\mathrm{O} ; 2$

[26] J. Joss and A. Waldvogel, "Raindrop Size Distribution and Sampling Size Errors," Journal of the Atmospheric Sciences, Vol. 26, No. 3, 1969, pp. 566-569. doi:10.1175/1520-0469(1969)026<0566:RSDASS $>2.0 . C$ $\mathrm{O} ; 2$

[27] D. Atlas, R. C. Srivastava and R. S. Sekhon, "Doppler Radar Characteristics at Vertical Incidence," Reviews of Geophysics, Vol. 11, No. 1, 1973, pp. 1-35. doi:10.1029/RG011i001p00001

[28] R. A. Houze Jr., "Cloud Dynamics," Academic Press, New York, 1993.
[29] M. Steiner, R. A. Houze Jr. and S. E. Yuter, "Climatological Characterization of Three-Dimensional Storm Structure from Operational Radar and Rain Gauge Data," Journal of Applied Meteorology, Vol. 34, No. 9, 1995, pp. 1978-2007. doi:10.1175/1520-0450(1995)034<1978:CCOTDS $>2.0 . C$ $\underline{\mathrm{O} ; 2}$

[30] A. Waldvogel, "The $\mathrm{N}_{0}$ Jump of Raindrop Spectra," Journal of the Atmospheric Sciences, Vol. 31, No. 4, 1974, pp. 1068-1078. doi:10.1175/1520-0469(1974)031<1067:TJORS >2.0.CO; $\underline{2}$

[31] M. Gosset, E.-P. Zahiri and S. Moumouni, "Rain Drop Size Distribution Variability and Impact on X-Band Polarimetric Radar Retrieval: Results from the AMMA Campaign in Benin," Quarterly Journal of the Royal Meteorological Society, Vol. 136, No. S1, 2010, pp. 243-356. doi:10.1002/qj.556

[32] R. Uijlenhoet, "Raindrop Size Distributions and Radar Reflectivity-Rain Rate Relationships for Radar Hydrology," Hydrology and Earth System Sciences, Vol. 5, No. 4, 2001, pp. 615-627.

[33] C. W. Ulbrich and D. Atlas, "Radar Measurements of Rainfall with and without Polarimetry," Journal of Applied Meteorlogy Climate, Vol. 31, No. 4, 2008, pp. 1067-1078. doi:10.1175/2007JAMC1804.1.

[34] V. Chandrasekar, R. Meneghini and I. Zawadzki, "Global and Local Precipitation Measurements by Radar. Radar and Atmospheric Science: A collection of Essays in honor of David Atlas," Meteorology Monograohy, No. 52, American Meteorology Society, 2003, pp. 215-236.

[35] W. J. Heinrich, J. Joss and A. Waldvogel, "Raindrop Size Distributions and the Radar Bright Band," Journal of Applied Meteorology, Vol. 35, No. 10, 1996, pp. 1688-1701. doi:10.1175/1520-0450(1996)035<1688:RSDATR $>2.0 . \mathrm{C}$ $\underline{\mathrm{O} ; 2}$

[36] C. W. Ulbrich and D. Atlas, "Microphysics of Raindrop Size Spectra: Tropical Continental and Maritime Storms," Journal of Applied Meteorology and Climatology, Vol 46, No. 11, 2007, pp. 1777-1791. doi:10.1175/2007JAMC1649.1

[37] A. D. Ochou, A. Nzeukou and H. Sauvageot, "Parametrization of Drop Size Distribution with Rain Rate," Atmospheric Research, Vol. 84, No. 1, 2007, pp. 58-66. doi:10.1016/j.atmosres.2006.05.003 